\title{
The Act of Improvisation within the Work of Tacita Dean
}

\section{Andrew Sneddon}

\section{Introduction}

This paper sets out to explore the work of Tacita Dean in order to discuss the use of improvisation within visual art. Dean's working method has shaped her thinking and practice over a number of years and is of particular interest within the visual arts. Dean welcomes situations that lead to the need to improvise, whereby improvisation is understood as "the exercise of care, judgment and dexterity [...] where the practitioner has continually to make adjustment to keep on course, in response to a sensitive monitoring of the conditions of the task as it unfolds" (Ingold and Hallam 13).

Observing Dean's exhibition project, An Aside (2005), and three of Dean's own projects—Banewl (1999), Diamond Ring (2002), and Presentation Sisters (2005), my aim is to consider Dean's choice of words as she welcomes chance, contingency, and chaos in her own work in order to develop a new understanding of how sagacity might foreground the significance of improvisation within contemporary art practice. Sagacity is defined here as sage-like, as having the wisdom to recognize potentially generative moments of risk. By considering the "dilettante" curatorial approach to choosing works for the exhibition An Aside, Dean states that her method "veered from the intuitive to the social, and from the orthodox to the inexplicable" (4). Some of the selected works failed to materialize, presenting the artist with an opportunity to improvise and to make serendipitous discoveries underpinned by sagacity, in turn yielding unexpected relationships within the exhibition and its accompanying catalogue.

\section{Improvisation and An Aside}

Visual artists often make significant decisions within their practice based on intentions or actions that are not turning out as expected or hoped. Taking materials designated for one purpose and using them for another, harnessing chance discoveries, or recognizing that potential mistakes can lead to new discoveries and realizations; these might all be seen as forms of improvisation. But are everyday strategies of making do, day-today studio shifts of direction, and damage limitation unproblematically related? Is there a difference between a work that accepts chance as a residual element and one that approaches it as integral and formative? Can we identify different notions of "objective" (and indeed "non-objective") chance?

Anthropologist Michael Agar provides one possible framework for thinking through some of these questions. Suggesting how ethnographers might work towards an understanding of what is valued and not valued within a community, he offers four registers within qualitative research that through the process of serendipity can convert "good fortune" or happenstance into significant and important findings. Calling these registers "occasioned," "core," "derivative," and "mandated," he sees them as four stages or breakdowns within the research process. In Agar's 1982 essay, "Towards an Ethnographic Language," he attempts to develop a general way to talk about ethnography, as he considers the problems faced by ethnographers as both interesting and at the same time almost embarrassing. He is concerned that two studies of similar groups may differ from each other, and that comparing different ethnographers' reports, supposedly about the "same" thing, would be confusing. He also identifies the way an ethnographer's training, experience, and personal history is liable to make any generalization even more difficult. He uses the example of Freudian theorists and kinship specialists to suggest how difficult they would be to compare, as they would be interested and pay attention to different aspects of a study.

Agar goes on to identify the importance within ethnographic study of expectations not being met, so that the unexpected emerges. He also suggests that the process by which a breakdown emerges and travels towards understanding should be called "resolution" and goes on to say that the process of resolution is an emergent one triggered by the breakdown. Agar's observations rest clearly within ethnography but provide a very useful framework to help understand how artists who court the unexpected (in this particular case, Tacita Dean) work towards resolving practice that necessitates improvisational tactics. The occasioned breakdown within ethnographic practice might simply be those issues that emerge in the course of doing ethnography. Core breakdowns are discoveries that make up the focus of the ethnographer's final report. Agar identifies the derivative breakdown as a series of discoveries that are not greatly significant or useful within the overall account of the project, but nevertheless are worthy of mentioning. The mandated breakdown would appear to be those discoveries that a project sets out to make. In a sense this type of breakdown is often viewed as "hypothesistesting" and is strongly related to initial intentions that encourage questioning one's understanding of situations. In what follows I have drawn on Agar's structure to consider an artist whose body of work openly courts the vagaries of improvisation within a practice.

An Aside takes its title from the theatrical convention in which an actor addresses the audience directly without interrupting the flow of action on stage. The play and the other characters are normally oblivious to the actor's 
independent dialogue with the audience, and the play continues over the course of the aside. Dean admits that sometimes the exhibition fits with this description and sometimes it doesn't. Curated group exhibitions organized by art historians and curators often follow a particular theme, a chronology, a perceived nationality, or a restrictive understanding of medium. An Aside is also sometimes referred to as "the exhibition without an idea," but a more apposite description within this context comes from Max Andrew in a review of the exhibition for Frieze Magazine: "An Aside-a hothouse of suspicion and bluff that festered with an off-key atmosphere of wayward anthropology." Art critic Adrian Searle describes Tacita Dean's curated group exhibition An Aside as "constructed almost as a picaresque novel might be, one thing leading to another by way of accident, serendipity and oblique association. Dean goes backwards and forwards in time, from place to place, one thing leading to another, discovering and recovering works one would never imagine seeing together." In a way that seems related to Agar's four registers of breakdowns-in particular the "occasioned," that which comes up in the course of the project serendipitously and moves to the centre of attention and becomes its core attraction-Searle clearly recognizes Dean's skill and experience, gained over time, in embracing these unknowns and converting them into known findings. The link between elements of Dean's practice and what can be described as "intuitive sagacity" will be discussed below in reference to the research of Daniel Liestman.

An Aside was an artist-curated exhibition project conceived by Roger Malbert and instigated by the Hayward Gallery's National Touring Exhibition program. This program also includes group exhibitions curated by Michael Craig-Martin's Drawing the Line (1995), Richard Wentworth's Thinking Aloud (1998), Susan Hiller's Dream Machines (2000), and Mark Wallinger's The Russian Linesman (2009).

These exhibitions, curated by high-profile and influential artists (as opposed to professional curators), allowed for a new approach to curatorial practice and afforded the artists the opportunity to experiment with alternative methods that might be closer to their own working methods evident in their studio practice. Searle articulates the tension between curator and artist/curator:

All too often, group exhibitions are a bore: strangled by "relevance" and spurious authority, the sense that some issue or other is being dealt with, definitively. These are bulwarks of the anxious curator. Artists often make the best curators, firstly because they have a better feel and engagement with objects and images, secondly because they are altogether quirkier, freer, by nature more interestingwhich is why they are artists in the first place. They think differently and have a more personal stake in looking at and thinking about art.

Dean draws upon the associative processes she uses in her practice to weave connections from one work to the next. These meandering narratives would appear to be concrete examples that embody the spirit of improvisation - taken here to mean the exercise of care, judgment, and dexterity-and to celebrate what the Surrealists called "Objective Chance." Unpredictable encounters, stories, recollections, and remembrance, combined with what Dean admits to be a "dilettante" (4) approach to the Surrealists' preferred modus operandi, provide the necessary guiding principles for the exhibition and accompanying publication. Throughout Dean's practice, as curator and as artist she attempts to develop tactics within her working method that remain openly receptive to the formation of unexpected confluences of thought that may not be accessible to those who must maintain certainty in order to keep anxiety at bay. Dean subscribes to André Breton's understanding of the objective chance process of "external circumstances acting in response to the unspoken desires and demands of the human psyche" (4). The artist is also wary of the fragility of this process and seeks to protect its immaterial existence and apprehensively relates to it as "explaining a dream, which invariably dies in the telling" (4).

Dean actively seeks out chance to a point that could be said to verge on superstition. Since she was seven or eight, the artist has had an ability to find four-leaf clovers and has built up a collection which has been exhibited alongside her other works:

I had always courted Chance, and the ease with which I found four-leaf clovers made me too sure of this special relationship. When I first showed my collection in 1995, for the first time in my collector's life, I became paralysed by an inability to find any more four-leafed clovers. It was as if I had turned the accidental action of finding a clover into something altogether too self-conscious. I had played an uncomfortable game with Fortune and she had shunned me for my ostentation. I suddenly searched too hard and could no longer find. (Dean $\mathrm{np}$ )

Dean says in her own words that she has "shown no fidelity to the true unconscious process: some of my decisions have been associative, while others feel they have been very formally arrived at" (4). I feel that there can be significant and useful parallels drawn between Dean's artistic practice and the writing of W.G. Sebald. Dean has made her interest and fascination with Sebald's writing widely known. The writer and the artist seem to share a common interest in apparently unrelated information combined with fortuitous discoveries. In conversation with Joseph Cuomo, Sebald talks about how The Rings of Saturn came about: 
But then as you go along, you find things. I think that's the advantage of walking. It's just one of the reasons I do that a lot. You find things by the wayside or you buy a brochure written by a local historian that is in a tiny local museum somewhere, which you would never find in London. And in that you find odd details, which lead you somewhere else, and so it's a form of unsystematic searching, which of course for an academic is far from orthodoxy, because we're meant to do things systematically. But I never liked doing things systematically. Not even my $\mathrm{PhD}$ research was done systematically. It was always done in random, haphazard fashion. (Sebald qtd. in Schwartz 94)

In the introduction to Searching for Sebald: What I Know for Sure, Lise Patt suggests that a wide range of postmedium artists who were laying the groundwork for a fictive genre in art quickly embraced Sebald's project. Adopting a process mediated by the foot, captured by the lens, and fuelled by the archive, these visual practitioners eschew mediums bound to traditional materials, adopting instead concepts that reached beyond the realms of art-particularly memory, trauma, and loss (Patt with Dillbohner 17). Lother Baumgarten's Da gefällts mir besser als in Westfalen (There I like it better than in Westphalia), El Dorado (1968-76) is credited by Dean for initiating the structure, as well as the concept, for An Aside. Baumgarten's work consists of slides detailing the vegetation, human rubbish, and documentation of spontaneous sculptures made in situ from material he would find while walking along a stretch of the Rhine between Düsseldorf and Cologne. These images were displayed alongside a soundtrack based on what he imagined the Amazonian jungle would sound like (he had never actually been there). A common element between Baumgarten's work and Dean's curatorial approach to An Aside is the embodiment of the Situationists' interest in wandering and wondering. This now-familiar attribute to psycho-geography is executed through the act of derive (drifting) (Knabb 50), and seems important in conditioning the mind in order to recognize serendipitous discoveries leading to acts of improvisation. These are all conscious tactics to focus attention on qualities of experience that would normally be consumed; they have no presence when we are caught up in a causal world and don't take time to wander.

Baumgarten's recollection of seeing a mysterious figure walking a dog along a stretch of the Rhine-a figure who later turned out to be fellow German artist Gerhard Richter-indirectly provided Dean with a starting point or cryptic clue towards suggesting another piece for the An Aside exhibition. Baumgarten suggests that a particular painting by Richter must surely have been inspired by the location. This sets Dean off on a quest to track down this painting. She fails to secure it for the exhibition, but in the act of tracking it down by thumbing through a catalogue of Richter drawings, she comes across drawings by another artist, Isa Genzken. Seeing these materials causes Dean to establish associations between them and Richter's and Blinky Palermo's dual portrait busts (Zwie Skulpturen fur einen Raum von Palermo [1971]). Her thought then relates Richter and Palermo's work with Joseph Beuys's self-portrait bust of 1947, followed by Marisa Mertz's head sculptures from the mid-tolate-1980s. This train of associations and connections could have gone in several directions, many of them potentially obvious, following the Richter painting and its possible origin. But Dean avoids these straightforward rational connections, and instead follows a more circuitous journey, adhering to the "dilettante" approach to decision making in visual art. It seems important here to acknowledge that the notion of the dilettante is referred to in a positive light as a form of wisdom-the conviction and confidence to comfortably ignore safe decisions in favour of riskier alternatives, or to choose unfamiliar and uncharted routes.

In a certain light, An Aside represents a series of improvisations. Dean instigates the project; she actively seeks out the unpredictable and the non-linear in ways that could not have been pre-imagined given the form of the exhibition or its significance, suggesting a creative inventiveness of the highest order: Her method entails a creative inventiveness of the highest order: "Nothing is more frightening than not knowing where you're going, but then again nothing can be more satisfying than finding you've arrived somewhere without a clear idea of the route" (Dean 4). But if, as already mentioned, improvisation seems to be in danger here of becoming a catch-all phrase, Michael Agar's ideas about ethnography provide a useful framework for distinguishing between (but also for integrating) different forms of unexpected situations or findings, triggering the need for the artist to improvise. The occasioned breakdown within the ethnographic process might simply be those issues that emerge in the course of doing ethnography. Within contemporary art practices, however, "occasioned" could be read as discoveries that naturally occur when one is involved in creative practices. For Agar, "core" breakdowns are discoveries that make up the focus of the ethnographer's final report. "Core" within art practice could suggest the discoveries that are evidenced within the final exhibition. "The derivative breakdown" that Agar identifies consists of discoveries that are not significant or useful within the overall account of the project, but are nevertheless worth mentioning. The "mandated" breakdown would appear to be those discoveries that the project sets out to make. This breakdown could be read as the artist's initial intention for the project to be undertaken.

Dean has referred to her welcoming of chance, chaos, and contingency as her working allies. However, I would like to suggest an alternative reading of her practice in terms of serendipitous and sagacious discovery coupled with an underlying risk of failure. For these reasons, I argue that Dean employs improvisational tactics. In a talk on Dean's work at The Common Guild in Glasgow, critic and curator Caoimhin Mac Giolla Leith also hesitated and questioned Dean's use of chaos within her work. He struggled to pinpoint active chaotic elements within her practice. There are certainly "breakdowns," to employ Agar's useful terminology; there are departures from the artist's initial intentions which create the unexpected, and the breakdown brings to attention interesting problems to be resolved by the artist. I suggest that these breakdowns are a form of failure, but a more positively 
conceived notion of failure than is commonly associated with the word: "when failure is released from being a judgemental term, and success deemed overrated, the embrace of failure can become an act of bravery, of daring to go beyond normal practices and enter a realm of not knowing" (Le Feurve 13).

Within the process of resolution of breakdown, Agar suggests that the emergence of such breakdowns needs to be understood with an openness and sensitivity to its newness. I feel that the use of "serendipity" and "sagacity" fits this state better than Dean's choice of the word "chance." "Serendipity" is typically misunderstood and used synonymously with "chance," "coincidence," "luck," or "providence." Equally, "the happy accident," the discovery of things without seeking them, is also attributed to serendipity. However, if we consider "serendipity" alongside the power of "sagacity," we get closer to Dean's familiar method of practice. The addition of "sagacity" to a description of Dean's method allows for the use and incorporation of knowledge and experience in the recognition of unexpected breakdowns.

Dean's ability to quickly assess and process the unexpected towards a new resolution could be described as a combination of divergent and convergent thinking, leading to new improvised ends. Dean seems to present the characteristics of a divergent thinker who can extract information from a variety of disciplines in order to arrive at a position with multiple options, a quality often seen as belonging to the more creative type. Dean, however, also has the well-developed presence of mind of the convergent thinker, who can arrive at a single correct solution to a potential problem.

It may seem strange to think of failure as a substantial component of the work of an artist who has just completed the twelfth commission in the Unilever Series for the Turbine Hall at Tate Modern, London. Dean was also nominated for the Turner Prize in 1998, and participated in the Venice Biennale in 2003 and 2005. But failing and unsuccessful endeavors can be traced back through many of Dean's works, in particular human failure in Disappearance at Sea (1996/97), the story of Donald Crowhurst and the Tiegnmouth Electron (2000), failed technology in Sound Mirrors (1999), and failed political ideology in Fernsehturrm (2001).

Failing and failure alongside error and mistakes are outcomes most would want to avoid, instead favouring success and achievement. In his 2010 talk at The Common Guild, Caoimhin Mac Giolla Leith introduced "Disappointment Avoidance Cultures" in relation to Dean's chosen approach to thinking about practice, the former being a concept developed by the psychoanalyst lan Craib in his 1994 book. The Importance of Disappointment where there is a suggestion that the expectation of never failing halts a healthy identity from developing and flies in the face of the common culture of our time to avoid the trauma of failure. This work in turn was inspired by the work of economist D.E. Bell (1985) and by Graham Loomes and Robert Sugden's "disappointment theory" (1982, 1986, 1987).

The feeling of disappointment is similar to the feeling of regret and is often considered the same emotion, but it is in fact quite different. Someone feeling regret focuses on how his or her poor choice contributed to the unwanted outcome, whereas someone feeling disappointed at his or her failure focuses on the outcome itself:

"Disappointment is created by comparing the actual outcome with prior expectations. It is related to the sense of loss or gain incurred by resolution of a chosen alternative" (Bell, "Disappointment" 117-20).

According to Wilco W. van Dijk and Marcel Zeelenberg, regret and disappointment following failure are the two emotions that are most closely linked to decision-making (van Dijk and Zeelenberg 321). Avoiding failure is often at the heart of many major decisions, as there is usually an element of uncertainty and unpredictability present. To fail in business, commerce, or industry typically has negative status and undesirable implications. However, within the realm of art, failure would appear to have a different register altogether. Lisa Le Feuvre suggests, "The inevitable gap between intention and realization of an artwork makes failure impossible to avoid. This very condition of art-making makes failure central to the complexities of artistic practice and its resonance with the surrounding world. Through failure one has the potential to stumble across the unexpected" (12). A more constructive concept of critically thinking about failure would be to avoid seeing it in terms of negative judgement, to avoid seeing its negative implications and to instead embraces its potential to provide an opportunity to reassess and reflect. Failed attempts thus become moments of growth rather than endpoints, for as Samuel Beckett writes, "Ever tried. Ever failed. No matter. Try again. Fail again. Fail better" (Beckett 7).

\section{Case Studies}

The first of our case studies exploring concrete examples of the artist's ability to embrace improvisation is Banewl (1999), a 63-minute,16mm colour anamorphic film with optical sound, filmed during the total eclipse of the sun at Brunewhall Farm, St. Buryan, Cornwall, 11 August 1999. 


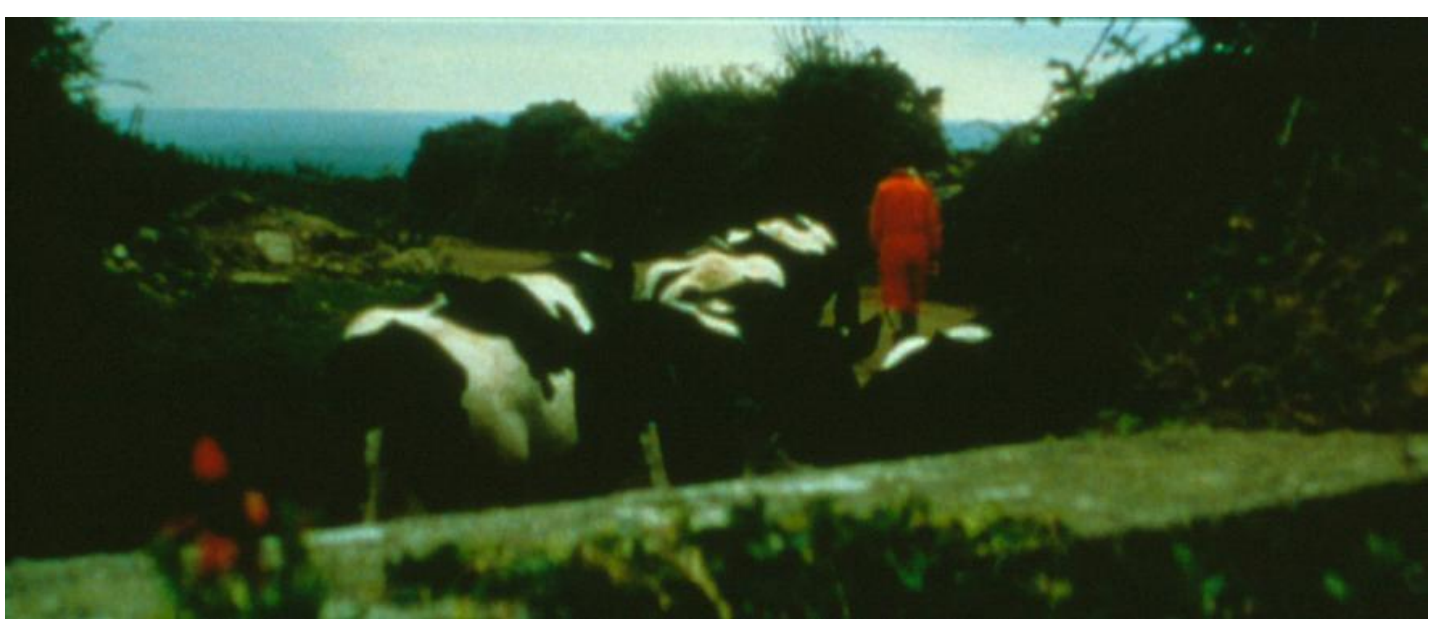

Banewl (1999)

$16 \mathrm{~mm}$ colour anamorphic with optical sound, 63 minutes.

Courtesy of the artist, Frith Street Gallery, London and Marian Goodman Gallery, New York / Paris.

Dean states that she intended to make a two-hour and forty-four-minute film-the same length of time as the total eclipse of the sun on that day. As with much of Dean's practice, there is meticulous planning involved in getting ready to film the eclipse. But on this occasion, as the time of the eclipse grew close, the unexpected and unwelcomed happened: it began to rain. At the same time, one of the four cameras suddenly malfunctioned, which seems to have instigated a cacophony of frantic exchanges between camera crews and the artist. Oblivious to the failing technology and quickly fading artistic concept, the animals from the immediate environment began to sense the brooding atmosphere of the imminent eclipse before the artist did. Dean recalls, "The swallows perceive the darkness coming long before us. Suddenly they go crazy. Swooping and darting in all directions, and then they disappear. The cows start to lie down one by one across the field. The temperature drops" (Dean np).

Dean's initial intention to film the sky in order to capture the totality was thwarted when the sky became overcast and adverse weather conditions set in. The necessity to improvise became apparent and Dean began to direct camera crews to film what was happening on the ground, as opposed to the events taking place in the sky. Inadvertently, Banewl presents the viewer with a remarkable record of a place at a particular time. By not focusing the film on the sun as initially planned, the resulting film reminds us of the deep, almost primordial knowledge of animals and a sense of place that is sensitive to a particular time.

Our second case study follows directly from Dean's desire to finally record a total eclipse of the sun, this time in Madagascar. Diamond Ring (2002) is a film that has helped Dean formulate a philosophy that suggests being "borne out of much necessity," for "sometimes things need to go wrong in order for them to go right" (Dean np). Again, after detailed plans were made to capture the two-and-a-half-minute eclipse, in the end all didn't go as planned. Human error this time had a say in the final outcome. The tripod holding the camera was knocked over at the crucial moment, again forcing Dean to improvise within minutes of the eclipse beginning. The intended plan being to have the locked-off camera position trained on the total eclipse, Dean found herself having to manually zoom in, a method she did not prefer. The nature of the filming process captured the bleached corona of the eclipse, again an unexpected and unimaginable outcome.

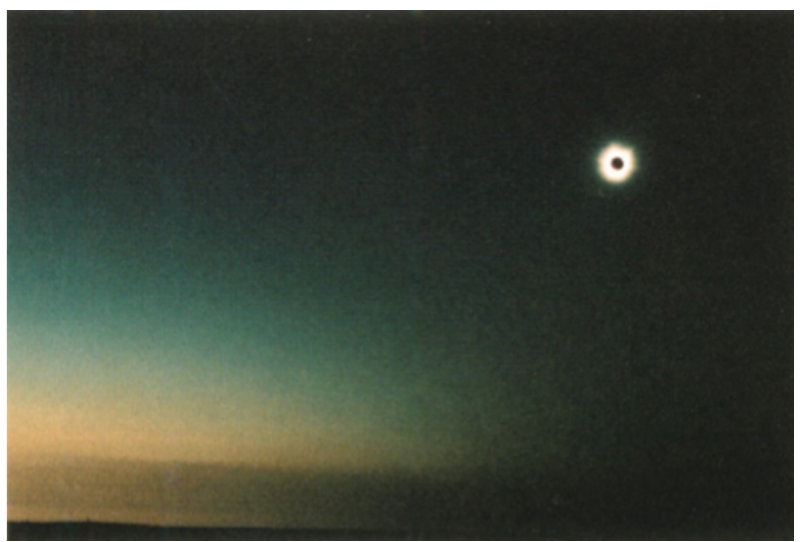

Diamond Ring (2002)

$16 \mathrm{~mm}$ colour film, mute, 6 minutes (cycle of 12 films each 27 seconds).

Courtesy of the artist, Frith Street Gallery, London and Marian Goodman Gallery, New York / Paris. 
A final case study is worth noting here, which involves the unexpected narrowing of the gap between a work's intention and its realization. In 2005, Dean was invited to make a response to the location of Cork as part of the City of Culture festival. The festival organizers considered the Titanic Centre an obvious place to which Dean could respond-a place where she might be interested in creating a work. While visiting places of interest for potential proposals, Dean unexpectedly caught sight of a nuns' graveyard. Instantly taken by the small site, she noticed that there was one missing gravestone-an empty space. This was the inspiration and catalyst for a new work that was to be called The Last Plot, and would chart the life and possible death of the nuns in the convent with the last plot in mind.

In the time between deciding on the concept and arriving back in Cork, a nun had passed away and had taken up the last plot. With this new development in mind, Dean decided to continue to film the life of the nuns in their slowly-vanishing world, and to record their domestic chores and ritual activity in a one-hour film called Presentation Sisters.

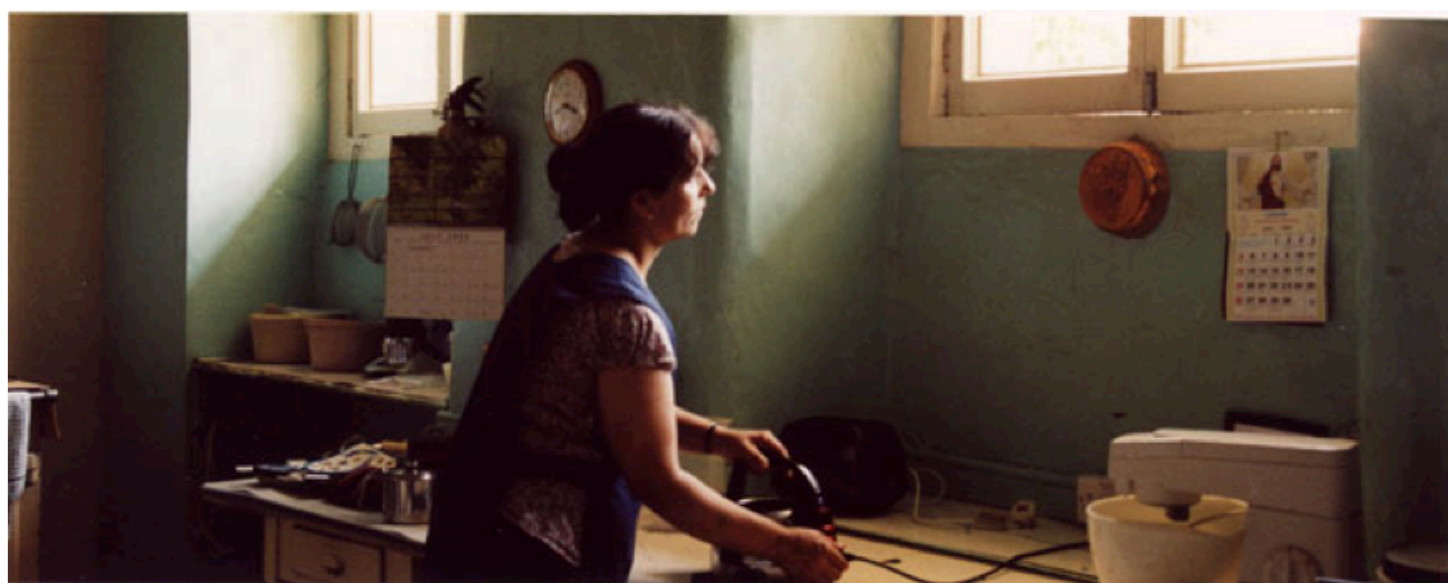

Presentation Sisters (2005)

$16 \mathrm{~mm}$ colour film, silent, 11 minutes.

Courtesy of the artist, Frith Street Gallery, London and Marian Goodman Gallery, New York / Paris.

Through reflecting on her own practice, Dean has noted, "chance, chaos and contingency are my working allies and I have learnt to welcome the uninvited and to allow the unimaginable" (Dean $\mathrm{np}$ ). This self-reflection on the creative process invites further analysis of how chance discoveries and detours down blind alleys and cul-desacs, alongside perceived failures of practice become seamlessly embedded and incorporated into the creative process. Dean draws upon ideas and concerns from other disciplines, such as science, medicine, and anthropology, which take into account the value of both serendipitous discovery and failure. This technique allows new opportunities and useful terminology to emerge in order to examine the role of improvisation in the visual art of Dean.

\section{Sagacity, Serendipity, and Improvisation}

Grasping the significance of improvisation within contemporary visual art practice requires that we develop a new understanding of how the prepared mind might use sagacity to unpack key stages leading to improvisation. Agar's notion of defining breakdowns, brought about by rupturing the expectations through potential failures between intention and realization, is a useful component towards this new understanding.

The acknowledgement and understanding of how improvisation requires and develops the skill of sagacity-defined as the wisdom to recognize something risky, particularly in response to unimaginable serendipitous discoveries-is key to decision-making within creativity.

The introduction of the word "serendipity" into the English language is relatively recent. The English novelist and politician Horace Walpole is credited with its coinage in a letter to the British diplomat, Horace Mann, dated from 1754. Inspired by reading The Three Princes of Serendip, Walpole was intrigued by the prince's ability to make fortuitous discoveries by accident, to recognize through his sagacity the value of things that he was not initially looking for:

This discovery indeed is almost of that kind which I call serendipity, a very expressive word, which as I have nothing better to tell you, I shall endeavour to explain to you: you will understand it better by the derivation than by the definition. I once read a silly fairy tale, called The Three Princes of Serendip: as their Highnesses travelled, they were always making discoveries, by accidents \& sagacity, of things which they were not in quest of: for instance, one of them discovered that a mule blind in the right eye had travelled the same road lately, because the grass was eaten only on the left side, where it was 
worse than on the right-now do you understand Serendipity? One of the most remarkable instances of this accidental sagacity (for you must observe that no discovery of a thing you are looking for comes under this description). (Merton and Barber 2)

Although Walpole is credited with the word's coinage, the sociologist Robert Merton must be credited with the serendipity pattern and its distribution and acceptance across the disciplines, from the sciences to the humanities:

The serendipity pattern refers to the fairly common experience of observing an unanticipated, anomalous and strategic datum which becomes the occasion for developing a new theory or for extending an existing theory. [...] The datum is, first of all, unanticipated. A research directed toward the test of one hypothesis yields a fortuitous by-product, an unexpected observation which bears upon theories not in question when the research was begun. Secondly, the observation is anomalous, surprising, either because it seems inconsistent with prevailing theory or with other established facts. In either case, the seeming inconsistency provokes curiosity [...] And thirdly, in noting that the unexpected fact must be strategic, i.e., that it must permit of implications which bear upon generalized theory, we are, of course, referring rather to what the observer brings to the datum than to the datum itself. For it obviously requires a theoretically sensitized observer to detect the universal in the particular. (1968, 157-62)

Our contemporary understanding of serendipity might be summed up as "accidental discovery." Walpole's recollection of The Three Princes of Serendip certainly speaks to this understanding: "they were always making discoveries, by accident and sagacity, of things they were not in quest of" (Merton and Barber 108). Merton suggests that Walpole realizes that this type of discovery is simply an example of inductive abilities. I suggest that the catalyst leading to important discoveries might be the introduction of sagacity in conjunction with serendipity.

In The Art of Scientific Investigation, W.I. Beveridge considers scientific breakthrough and the significant presence of chance coupled with sagacity, and suggests "[t]hey are the more remarkable when one thinks of the failures and frustrations usually met in research. Probably the majority of discoveries in biology and medicine have been come upon unexpectedly, or at least had an element of chance in them, especially the most important and revolutionary ones" (Beveridge 31 ). When examining what role serendipity has played in scientific discoveries, it is difficult to escape the story of Fleming's discovery of penicillin. It is now known that several scientists had noticed the inhibition of staphylococcal colonies, but had treated it as a nuisance, and had ignored or missed its significance; but Fleming made the connection due to his perspicacity, and seized the opportunity others had let pass (34).

The importance and significance of serendipity and sagacity seems well recorded in the sciences. There now seems to be a new interest in how these connections might be harnessed from information-seeking and information-retrieval disciplines such as library research or internet development. Tacita Dean recalls visiting a lecture and being disappointed to hear the following: "We're never out of ideas. We can suggest things that are interesting to you, based on your passions, things that you care about, where you're going, that sort of thing. Our suggestions will be pretty good. We have figured out a way to generate serendipity. We actually understand now how we can surface things that are surprising to you, but based on things that you care about and what other people care about" (23). Daniel Liestman describes the ability to discover connections that are not always apparent, but favour the prepared mind and "intuitive sagacity" which comes from "a random juxtaposition of ideas in which loose pieces of information frequently undergo a period of incubation in the mind and are brought together by the demands of some external event, such as a reference query, which serves as a catalyst" (530). The notion of the incubating an idea seems to fit well with percolation of an idea in the mind of an artist for a period, only to be activated and brought into being in the world by external events as a response to a particular context, or, as we have seen in Tacita Dean's work, "when things go wrong," triggering improvisation in order for them to go right.

\section{Conclusion}

In studying the nature of improvisation as a curatorial methodology, I have considered the group exhibition An Aside. Through Dean's alternative and "dilettante" approach to curating An Aside, which involved relying upon chance events and intuitive sagacity, she has shown that the unforeseen can allow the unimaginable to emerge. It's also important to remember that the unimaginable would not be achievable if it were not possible to improvise with care, judgment, and dexterity. Also, by reflecting on a selection of concrete examples of Tacita Dean's own creative practice in order to understand the nature of improvisation in contemporary art practice, I have suggested that there is a tripartite structure at play. I've suggested that this structure incorporates failure, serendipity, and sagacity, leading to Improvisation. By visiting a number of key works by Dean, where initial failure or unforeseen circumstances in achieving the intended outcomes of projects have been turned to new unexpected resolutions. These circumstances have allowed for the importance of serendipity and sagacity in the decision making process of the artist to be explored. The resulting improvisation demonstrates the value of 
intuitive sagacity in this tripartite structure. Mac Giolla Leith references Dean commenting on her practice in this particular manner: "uninvited disappointments which are unbelievably painful at the time become productive in hindsight" (Mac Giolla Leith). Within Dean's own practice thus exists a "Sebaldian paradigm": the allocation of trust and confidence in circuitous routes and wandering and wondering. I believe this confidence could be read as the equivalent of trust in her ability to improvise, accumulated over time through a tacit understanding of practice and possibilities.

Although Dean doesn't actively court failure, she has learnt to accept disappointment and to build it into her practice as a positive element. As Hans-Joachim Müller has observed, "having a goal after the goal means that, in fact, the goal you failed to reach cannot have been the ultimate, perfect one" (Müller 10). Equally, Dean has accepted chance encounters of a serendipitous nature and has found ways of incorporating them into her own practice. The use of intuitive reasoning in the form of sagacity is an important, latent skill that leads directly to effective and creative improvisation.

\section{Works Cited}

Agar, Michael H. “Toward an Ethnographic Language." American Anthropologist 84.4 (1982): 779-95. Print.

Andrew, Max, “An Aside.” Frieze Magazine 91 (May 2005). Web. 29 Oct. 2012. http://www.frieze.com/issue/review/an_aside/.

Beckett, Samuel. Worstward Ho. London: Calder Publications Ltd, 1984. Print.

Bell, D.E. "Disappointment in decision making under certainty." Operations Research 33 (1985): 1-27. Print.

Beveridge, W.I. The Art of Scientific Investigation. New York: Random House (Vintage), 1957. Print

Craib, Ian. The Importance of Disappointment. London: Routledge, 1994. Print.

Dean, Tacita. Selected Writings: Tacita Dean. Paris: Pais-Musees, editions des musées de la Ville de Paris, Steidl Publishing, 2003. Print.

Dean, Tacita. An Aside: Selected by Tacita Dean. London: Hayward Gallery Publishing, 2005. Print.

Ingold, Tim and Elizabeth Hallam. "Creativity and Cultural Improvisation: An Introduction." Creativity and Cultural Improvisation. Ed. Elizabeth Hallam and Tim Ingold. Oxford: Berg, 2007. 1-24. Print.

Le Feurve, Lisa, ed. Failure. Cambridge, USA: MIT Press, 2010. Print.

Liestman, Daniel. "Chance in the Midst of Design: Approaches to Library Research Serendipity." RQ 31 (1992): 524-32. Print.

Loomes, Graham and Robert Sugden. "Disappointment and Dynamic Inconsistency in Choice under Uncertainty." Review of Economic Studies 53 (1986): 271-82. Print.

---. "Regret Theory: An Alternative Theory of Rational Choice under Uncertainty." Economic Journal 92 (1982): 805-24. Print.

---. "Testing for Regret and Disappointment in Choice under Uncertainty." Economic Journal 97 (1987): $118-29$. Print.

Mac Giolla Leith, Caoimhin. On Tacita Dean. Web. 28 Oct. 2012.

http://www.thecommonguild.org.uk/2010/12/caoimhin-mac-giolla-leith-on-tacita-dean/

Merton, R.K. and Elinor Barber. The Travels and Adventures of Serendipity: a study in sociological semantics and the sociology of science. Princeton: Princeton UP, 2004. Print.

---. Social Theory and Social Structure. New York: Free Press, 1968. Print.

Müller, Hans-Joachim. The Art of Failure. Basel: Kunsthaus Baselland, 2009. Print.

Patt, Lise with Christel Dillbohner. Searching for Sebald: Photography after W.G. Sebald. Los Angeles: The Institute of Cultural Inquiry, 2007. Print. 
Searle, Adrian. "Fancy seeing you here...” The Guardian 1 Mar. 2005. Web. 25 Oct.2012. http://www.guardian.co.uk/culture/2005/mar/01/1.

Schwartz, Lynne Sharon, ed. The Emergence of Memory: Conversations with W.G. Sebald. New York: 7 Stories Press, 2007. Print.

van Dijk, Wilco W. and Marcel Zeelenberg. "Investigating the Appraisal Pattern of Regret and Disappointment." Motivation and Emotion 26.4 (2002): 321-31. Print. 